\title{
Significance of delta agent infection in chronic hepatitis $B$ virus infection: a study in British carriers
}

\author{
I V D WELLER, P KARAYIANNIS, A S F LOK, L MONTANO, \\ M BAMBER, H C THOMAS, AND SHEILA SHERLOCK
}

From the Department of Medicine, Royal Free Hospital and School of Medicine, London

SUMmaRY Delta antigen $(\delta)$ is a transmissible agent requiring hepatitis B virus (HBV) for its replication. Antibody to $\delta$ (anti- $\delta$ ) was present in nine of $71(13 \%)$ British HBV carriers: six were intravenous drug abusers and two were haemophiliacs. Anti- $\delta$ was negative in $30 \mathrm{HBs} A g$ positive homosexuals. Cirrhosis was common in patients with anti- $\delta$ and those with anti- $\delta$ positive cirrhosis were significantly younger than those with anti- $\delta$ negative cirrhosis. In British HBV carriers $\delta$ infection is associated with intravenous drug abuse and haemophilia and perhaps a more rapid progression of chronic liver disease.

Delta antigen $(\delta)$ was discovered by direct immunofluorescence in hepatocyte nuclei of Italian patients with chronic hepatitis B virus (HBV) infection; it is distinct from other HBV antigens. ${ }^{1}$ Hepatitis B virus carriers with $\delta$ in the liver have a serum antibody (anti- $\delta$ ) in high titre detectable by radioimmunoassay and $\delta$ itself has been extracted from liver and serum. ${ }^{2-4}$ Delta antigen from liver is a protein of 68000 daltons. $^{2}$ In serum it is associated with a low molecular weight RNA encapsulated by hepatitis B surface antigen ( $\mathrm{HBsAg}$ ) in a $35-37 \mathrm{~nm}$ subpopulation of particles. ${ }^{3}{ }^{4}$ Studies in chimpanzees suggest that $\delta$ is a marker of a transmissible pathogenic agent, either a variant of $\mathrm{HBV}$ or another virus which requires $\mathrm{HBV}$ for its replication. ${ }^{56}$ Anti- $\delta$ is prevalent in Italian HBV carriers and more common in patients with chronic liver disease. ${ }^{7}$ The prevalence of anti- $\delta$ in British HBV carriers is unknown. The aim of this study was to determine whether $\delta$ infection is common in British HBV carriers and its significance in terms of predicting the severity of chronic liver disease.

\section{Methods}

\section{PATIENTS}

Seventy one HBsAg carriers born and resident in Great Britain were studied. Sixty four men and seven women; mean age 36 years (range 11-67 years). Forty five were $\mathrm{HBeAg}$ and 26 anti-HBe

Address for correspondence: Dr H C Thomas. The Royal Free Hospital. Pond Street. London NW3 2QG.

Received for publication 28 January 1983 positive. Fifty nine patients had abnormal liver function tests and 50 histologically proven chronic liver disease (nine chronic persistent and 28 chronic active hepatitis, eight active and five inactive cirrhosis). The patients included 30 male homosexuals, 10 intravenous drug abusers, and three haemophiliacs. Serum taken at the time of liver biopsy and in 16 patients multiple samples taken over one to four years were stored at $-20^{\circ} \mathrm{C}$. Serum was also collected from 100 British blood donors, 79 British haemophiliacs and 58 British intravenous drug abusers, all were $\mathrm{HBsAg}$ negative.

$\mathrm{HBs} \mathrm{Ag}, \mathrm{HBeAg}$, anti-HBe, anti-HBc, and antiHBs were detected by radioimmunoassay (Abbott). Sera were coded and sent for 'blind' analysis for anti- $\delta$ to Dr Mario Rizzetto (Turin, Italy). Anti- $\delta$ was detected and titred by a solid phase blocking radioimmunoassay $^{2}$ (titres $>1: 10^{3}$ indicate current infection and $<1: 10^{3}$ past infection, with $\delta$ ).

Liver biopsies from six anti- $\delta$ positive and 10 anti- $\delta$ negative carriers were embedded in OCT and snap frozen. Five microns thick cryostat sections were fixed in acetone/chloroform, lyophilised for two hours and then stained for $\delta$ antigen by direct immunofluoresence with a fluoresceinisothiocyanate (FITC) labelled antiserum to $\delta$ (donated by Dr M Rizzetto). The preparation and specificity of this antiserum has been described. ${ }^{18}$

\section{Results}

HBSAG POSITIVE CARRIERS

Anti- $\delta$ was positive in nine of 71 carriers (13\%) 
(Table 1). In the carriers in whom multiple serum samples were analysed over several years, three were anti- $\delta$ positive and 13 anti- $\delta$ negative on all specimens. Of the nine anti- $\delta$ positive carriers four were $\mathrm{HBeAg}$ and five anti-HBe positive, six were intravenous drug abusers, and two were haemophiliacs. The ninth was a 52 year old heterosexual male with cirrhosis and primary hepatocellular carcinoma who had never abused drugs. Eight patients had anti- $\delta$ titres of $>1$ in $10^{3}$ and one a titre of $<1$ in $10^{3}$. Delta antigen was detected in all six liver biopsies from these anti- $\delta$ positive carriers and in none of the 10 anti- $\delta$ negative carriers (Figure).

None of the 30 homosexual males was anti- $\delta$ positive. The prevalence of anti- $\delta$ in the nonhaemophiliacs, non-intravenous drug abuser carriers was one of $58(2 \%)$.

Cirrhosis was common in anti- $\delta$ positive carriers that had liver biopsies; four of seven compared with nine of 46 in the anti- $\delta$ negative carriers (Table 2). The four with anti- $\delta$ positive cirrhosis were significantly younger $(30,31,30$, and 52 years) than the nine with anti- $\delta$ negative cirrhosis (median 56 years, range 33-67 years, $p<0.05$, Wilcoxon's rank sum test). The 31 year old carrier with anti- $\delta$ positive cirrhosis died recently, six months after the biopsy, with end stage liver disease. Of the other five anti- $\delta$ positive patients three had a chronic active hepatitis and two had raised transaminases but no biopsy was taken (one was a haemophiliac and the other a drug addict who refused). None of the carriers with normal liver function tests and/or minimal change
Table 1 Prevalence of anti- $\delta$ in patient groups

\begin{tabular}{lrll}
\hline Patient group & No & $\begin{array}{l}\text { Anti- } \delta \\
\text { positive }\end{array}$ & $\%$ \\
\hline HBsAg-positive carriers & & & \\
$\quad$ Male homosexuals & 30 & 0 & \\
$\quad$ Intravenous drug abusers & 10 & 6 & \\
Haemphiliacs & 3 & 2 & \\
Others & 28 & 1 & 13 \\
Total & 71 & $9^{*}$ & \\
HBsAg-negative controls & 100 & 0 & 0 \\
$\quad$ Blood donors & 79 & 0 & 0 \\
$\quad$ Haemophiliacs & 58 & $2+$ & 3 \\
$\quad$ Intravenous drug abusers & & & \\
\hline
\end{tabular}

${ }^{*}$ Titres $>1$ in $10^{3}$.

+ Titres $<1$ in $10^{3}$.

on biopsy (12) or chronic persistent hepatitis (nine) had anti- $\delta$.

HBSAG NEGATIVE BLOOD DONORS, HAEMOPHILIACS, AND DRUG ADDICTS

None of the $100 \mathrm{HBsAg}$ negative blood donors and 79 haemophiliacs was anti- $\delta$ positive although 46 of the haemophiliacs had anti-HBs and/or anti-HBc. Two of the $58 \mathrm{HBsAg}$ negative intravenous drug abusers had anti- $\delta$ in low titre and both had anti-HBs and anti-HBc as did 39 of the other abusers.

\section{Discussion}

Nine out of $71(13 \%)$ of British HBsAg carriers
Figure Delta antigen staining in hepatocyte nuclei of an anti- $\delta$ positive drug abuser: direct immunofluorescence with anti$\delta$-FITC antiserum $(\times 346)$.

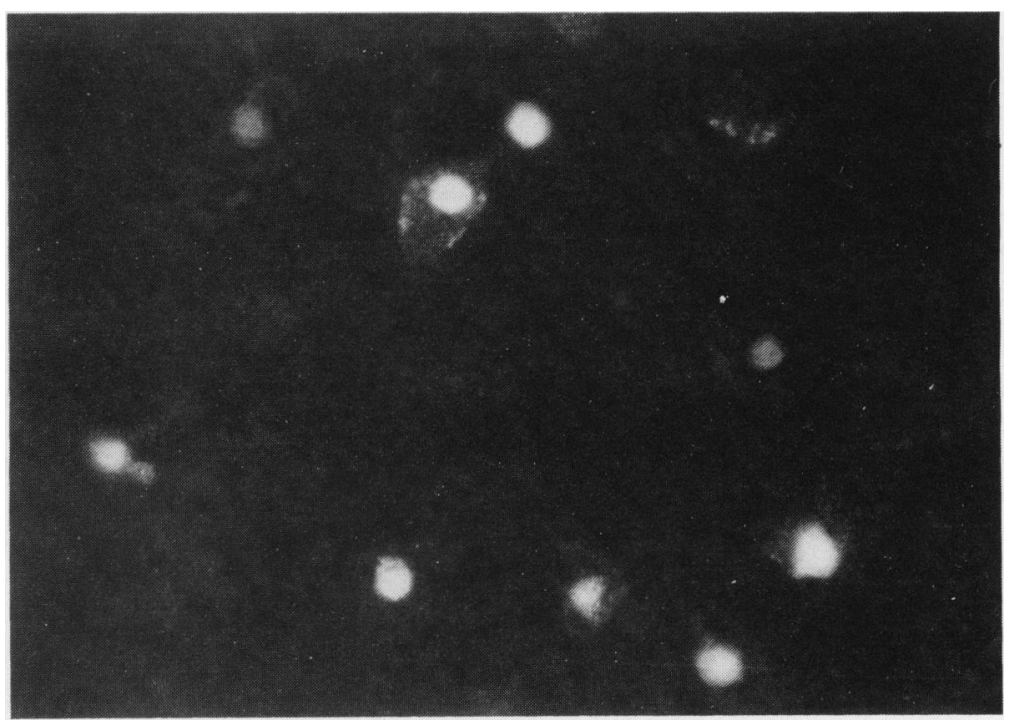


Table 2 HBsAg-positive carriers: liver histology in relation to $\delta$ infection

\begin{tabular}{llllllll}
\hline & $\begin{array}{l}\text { Normal LFTs } \\
\text { nobiopsy or } \\
\text { min change }\end{array}$ & $\begin{array}{l}\text { No } \\
\text { biopsy }\end{array}$ & $C P H$ & $C A H$ & $A C$ & IC \\
\hline Anti- $\delta-\mathrm{ve}$ & 12 & 7 & 9 & 25 & 5 & 4 \\
Anti- $\delta+\mathrm{ve}$ & 0 & 2 & 0 & 3 & 3 & 1 \\
\hline
\end{tabular}

$\mathrm{CPH}=$ chronic persistent hepatitis. $\mathrm{CAH}=$ chronic active hepatitis, IC = inactive cirrhosis, $\mathrm{AC}=$ active cirrhosis. LFTs $=$ liver function tests.

were anti- $\delta$ positive. The prevalence of anti- $\delta$ is high in Northern and Southern Italy (16-29\% and 59\% respectively) and low in Germany, Poland, and France (1-9\%). A very high prevalence was found in Scandinavia and two American states (23-47\%), but these populations contained a high proportion of intravenous drugs abusers and/or multiplytransfused subjects, ${ }^{7}$ who are more exposed to repeated $\mathrm{HBV}$ and therefore $\delta$ infection. ${ }^{9}{ }^{10}$ In our study eight of nine anti- $\delta$ positive patients were either intravenous drug abusers or haemophiliacs. Excluding these the prevalence is one out of 58 (2\%), more in keeping with other European studies. Two HBsAg negative drug abusers with evidence of past $\mathrm{HBV}$ infection had anti- $\delta$ in low titre and this is thought to be owing to a past infection with both hepatitis B virus and $\delta .^{9}$

All 30 homosexual men were anti- $\delta$ negative. This group, like intravenous drug abusers and haemophiliacs has a high incidence of HBV infection, and therefore might be expected to develop $\delta$ infection. This may be related to a lower innoculum of virus with sexual transmission allowing HBV but not $\delta$ infection. In the chimpanzee a $10^{-8}$ dilution of $\mathrm{HBV} / \delta$ containing serum has resulted in loss of $\delta$ but retention of $\mathrm{HBV}$ infectivity. ${ }^{3}$ An alternative possibility is that delta infection has not yet been introduced to a great extent into the homosexual population.

Cirrhosis was more common in patients with anti- $\delta$ than in those without and patients with anti- $\delta$ positive cirrhosis were significantly younger than those with anti- $\delta$ negative cirrhosis. This suggests that the presence of delta agent may be associated with a more rapid progression of chronic liver disease. Other factors associated with intravenous drug abuse and haemophilia, such as concomitant NANB virus infection, ${ }^{11} 12$ and an early age of initial HBV infection, may also play a role.

We thank Dr M Rizzetto for performing the anti- $\delta$ assay. IVDW was an MRC Training Fellow and is now lecturer in the Academic Department of Genitourinary Medicine, Middlesex Hospital. PK and MB were also supported by the MRC. ASFC and LM were supported by the University of Hong Kong and CONACYT Mexico respectively. HCT is a Senior Wellcome Fellow. This work was presented in part at the autumn meeting of the British Society of Gastroenterology, Leeds, 1982.

\section{References}

1 Rizzetto M, Canese MG, Arico S, Crivelli O, Bonino $F$, Trepo C, Verme G. Immunofluorescence detection of a new antigen-antibody system $(\delta /$ anti- $\delta$ ) associated with the hepatitis B virus in the liver and in the serum of HBsAg carriers. Gut 1977; 18: 997-1003.

2 Rizzetto M, Shih JW-K, Gerin JL. The hepatitis B virus-associated $\delta$ antigen: isolation from liver, development of solid-phase radioimmunoassays for $\delta$ antigen and anti- $\delta$ and partial characterisation of $\delta$ antigen. J Immunol 1980; 125: 318-24.

3 Rizzetto M, Hoyer B, Canese MG, Shih JW-K, Purcell RH, Gerin JL. $\delta$ agent: the association of $\delta$ antigen with hepatitis B surface antigen and RNA in serum of ס-infected chimpanzees. Proc Natl Acad Sci USA 1980; 77: 6124-8.

4 Bonino F, Hoyer B, Ford E, Shih JW-K, Purcell RH, Gerin JL. The $\delta$-agent: HBsAg particles with $\delta$ antigen and RNA in the serum of an HBV carrier. Hepatology 1981; 1: 127-31.

5 Rizzetto M, Canese MG, Gerin JL, London WT, Sly DL, Purcell RH. Transmission of the hepatitis B virus-associated delta antigen to chimpanzees. $J$ Infect Dis 1980; 141: 590-602.

6 Leading article. Delta agent - a virus in disguise. Lancet 1982; 1: 259-60.

7 Rizzetto M, Purcell RH, Gerin JL. Epidemiology of HBV-associated delta antigen. Geographical distribution and prevalence in poly-transfused $\mathrm{HBsAg}$ carriers. Lancet 1980; 1: 1215-8.

8 Stoecklin E, Gudat F, Krey G et al. $\delta$ antigen in hepatitis B: immunohistology of frozen and paraffinembedded liver biopsies and relation to $\mathrm{HBV}$ infection. Hepatology 1981; 1: 238-42.

9 Raimando G, Smedile A, Gallo L, Balbo A, Panzetto A, Rizzetto M. Multicentre study of prevalence of $\mathrm{HBV}$-associated delta infection and liver disease in drug addicts. Lancet 1982; 1: 249-51.

10 Rizzetto M, Morello C, Mannucci PM et al. Delta infection and liver disease in haemophiliac carriers of hepatitis B surface antigen. J Infect Dis 1982; 145: 18-22.

11 Knodel RG, Conrad ME, Ishak KG. Development of chronic liver disease after acute non-A, non-B post transfusion hepatitis. Gastroenterology 1977; 72: 902-9.

12 Bamber M, Murray A, Arborgh BAM, Scheuer PJ, Kernoff PBA, Thomas HC, Sherlock S. Short incubation non-A, non-B hepatitis transmitted by factor VIII concentrates in patients with congenital coagulation disorders. Gut 1981; 22: 854-9. 